\title{
A observação de aves como facilitador do ensino de Biologia
}

\author{
Bird watching as a Biology teaching facilitator \\ La observación de aves como facilitador de enseñanza de Biología
}

Recebido: 21/08/2021 | Revisado: 01/09/2021 | Aceito: 05/09/2021 | Publicado: 06/09/2021

\author{
Viviane Assunção da Silva \\ ORCID: https://orcid.org/0000-0003-4611-0590 \\ Universidade do Estado de Mato Grosso, Brasil \\ E-mail: viviane.assuncao@unemat.br \\ Josué Ribeiro da Silva Nunes \\ ORCID: https://orcid.org/0000-0003-3927-5063 \\ Universidade do Estado de Mato Grosso, Brasil \\ E-mail: josue@unemat.br \\ Paulo Sérgio Lopes da Silva \\ ORCID: https://orcid.org/0000-0002-9920-1915 \\ Instituto Federal de Mato Grosso, Brasil \\ E-mail: paulo.silva@jna.ifmt.edu.br
}

\begin{abstract}
Resumo
A escola contemporânea tem sofrido grande impacto diante das transformações ocorridas na sociedade, sendo impelida a buscar novas propostas de ensino, a fim de superar o fracasso escolar. Assim, na tentativa de imprimir significado a aprendizagem de biologia e torná-la mais eficaz, cada vez mais tem-se investido na utilização de espaços públicos não formais, afim de aproveitar a curiosidade e disponibilidade dos estudantes para que ocorra a consolidação do processo ensino-aprendizagem, aliando teoria e prática. Deste modo, este trabalho teve como objetivo evidenciar a observação de aves no Parque Lagoa da Garça em Juína-MT, como uma ferramenta válida para o ensino de biologia. Para tanto foi elaborada uma sequência didática envolvendo a realização de trilha interpretativa, onde estudantes puderam ser protagonistas do processo ensino-aprendizagem. Antes e posterior a execução do planejamento didático, os estudantes responderam questionários, denominados de pré-teste e pós-teste, que auxiliaram na verificação da validade do método didático empregado. Através das respostas dos estudantes, pode-se verificar que a atividade proposta possibilitou a eles conhecer mais sobre as espécies de aves locais, observando a importância ecológica destes animais e a estreita relação da diversidade deste grupo com o estado de conservação do ambiente em que eles vivem, oportunizando reflexões sobre atitudes humanas que impactam diretamente estes seres.
\end{abstract}

Palavras-chave: Espaços não formais de ensino; Observação de aves; Ensino de biologia; Ensino investigativo.

\begin{abstract}
The contemporary school has suffered a great impact due to the transformations that have taken place in society, being impelled to seek new teaching proposals in order to overcome school failure. Thus, in an attempt to give meaning to biology learning and make it more effective, more and more has been invested in the use of non-formal public spaces, in order to take advantage of the curiosity and availability of students so that the consolidation of the teaching process can occur. -learning, combining theory and practice. Thus, this work aimed to highlight the observation of birds in the Lagoa da Garça Park in Juína-MT, as a valid tool for teaching biology. For that, a didactic sequence was elaborated involving the accomplishment of an interpretative path, where students could be protagonists of the teaching-learning process. Before and after the execution of the didactic planning, the students answered questionnaires, called pre-test and post-test, which helped in verifying the validity of the didactic method used. Through the students' answers, it can be seen that the proposed activity allowed them to know more about the local bird species, noting the ecological importance of these animals and the close relationship of the diversity of this group with the conservation status of the environment in which they live, providing opportunities for reflections on human attitudes that directly impact these beings.
\end{abstract}

Keywords: Non-formal teaching spaces; Birds watching; Biology teaching; Investigative teaching.

\section{Resumen}

La escuela contemporánea ha sufrido un gran impacto debido a las transformaciones que se han producido en la sociedad, viéndose impulsada a buscar nuevas propuestas didácticas con el fin de superar el fracaso escolar. Así, en un intento por darle sentido al aprendizaje de la biología y hacerlo más efectivo, se ha invertido cada vez más en el uso de espacios públicos no formales, con el fin de aprovechar la curiosidad y disponibilidad de los estudiantes para que el Se puede producir la consolidación del proceso de enseñanza. - Aprendizaje, combinando teoría y práctica. Así, este trabajo tuvo como objetivo destacar la observación de aves en el Parque Lagoa da Garça en Juína-MT, como una 
herramienta válida para la enseñanza de la biología. Para ello, se elaboró una secuencia didáctica que involucró la realización de un camino interpretativo, donde los estudiantes pudieran ser protagonistas del proceso de enseñanzaaprendizaje. Antes y después de la ejecución de la planificación didáctica, los estudiantes respondieron cuestionarios, llamados pre-test y post-test, que ayudaron a verificar la validez del método didáctico utilizado. A través de las respuestas de los estudiantes, se puede apreciar que la actividad propuesta les permitió conocer más sobre las especies de aves locales, destacando la importancia ecológica de estos animales y la estrecha relación de la diversidad de este grupo con el estado de conservación del medio ambiente en que viven, brindando oportunidades para reflexionar sobre las actitudes humanas que impactan directamente a estos seres.

Palabras clave: Espacios docentes no formales; Observación de aves; Enseñanza de la biología; Docencia investigativa.

\section{Introdução}

A escola contemporânea tem sofrido grande impacto diante das transformações ocorridas na sociedade, sendo impelida a buscar novas propostas de ensino, a fim de não incorrer no chamado fracasso escolar. Tradicionalmente, os métodos utilizados em sala de aula baseiam-se na mera transmissão linear de conteúdo, sem envolvimento e participação ativa dos estudantes, assim como observado por Alves, Silva e Reis (2020). Este modelo didático conflita diretamente com os interesses e hábitos da sociedade atual que se baseia na globalização e está em constante transformação. Esse desencontro de interesses entre escola e sociedade acaba por gerar e até fortalecer o processo de exclusão social pois influencia diretamente na forma como o conhecimento é distribuído à população.

Na tentativa de diminuir o distanciamento existente entre escola e sociedade, os documentos que direcionam o ensino no Brasil e no Estado de Mato grosso (Lei de Diretrizes e Bases da Educação Nacional, Base Nacional Comum Curricular, Orientações Curriculares do Estado de Mato Grosso e etc.), tem enfatizado a necessidade da plena formação dos estudantes através do desenvolvimento de competências que mobilizem conhecimentos, habilidades, atitudes e valores que os auxiliem a resolver as demandas da vida cotidiana, levando-os a exercer a plena cidadania e os capacitando ao mundo do trabalho.

As "Orientações Curriculares Para o Ensino Médio", disponibilizadas pela Ministério da Educação em 2006 já ressaltavam para a necessidade do ensino significativo, destacando o fato de que o ensino de biologia deve nortear o posicionamento dos discentes frente a questionamentos polêmicos que podem interferir diretamente em suas condições de vida, a exemplo, a promoção de atividades que levem os alunos a perceberem a importância da grande diversidade biológica presente no Brasil, e como esse fato influencia a qualidade de vida do país e do mundo (Brasil, 2006). É fato que muitos jovens e adultos não conhecem, ou não percebem, a diversidade biológica presente nos espaços urbanos que frequentam, daí a necessidade da escola, enquanto instituição de ensino formal, adotar e utilizar estes ambientes para a prática pedagógica, promovendo o elo entre o conhecimento formal reproduzido na grade escolar e o conhecimento empírico trazido pelo estudante.

Nesta busca por um ensino de qualidade que seja significante para o estudante, há de se ter um cuidado especial no planejamento das atividades a serem desenvolvidas, principalmente no que se refere a abordagem didática que será utilizada. Ainda neste sentido, deve-se ressaltar que a Base Nacional Comum Curricular (BNCC) para o ensino médio, aprovada em dezembro de 2018, aponta entre as dez competências gerais da educação básica, a necessidade de exercitar a curiosidade intelectual dos estudantes, recorrendo a abordagem própria da ciência, incluindo a investigação, a reflexão, a análise crítica, a imaginação e a criatividade, levando-os a elaborar e testar hipóteses, formular e resolver problemas e criar soluções utilizando conhecimentos de diferentes áreas (Brasil, 2018). Assim, afim de se promover o ensino de biologia que atenda a competência citada acima, acredita-se que a adoção de práticas pedagógicas aliadas ao ensino por investigação, possam “... contribuir para que os estudantes desenvolvam não apenas entendimento sobre os conceitos, mas também, e sobretudo, habilidades cognitivas para a investigação de problemas que surjam em seu entorno" (Sasseron, 2015. p. 63) 
O ensino por investigação é uma abordagem didática que estimula o estudante a pensar, propor hipóteses e buscar possibilidades em meio a situações problemas, podendo ser aliada a diversos ambientes e outras metodologias. Carvalho, Vannucchi, Barros, Gonçalves e Rey (2005) ressaltam a importância do professor durante o desenvolvimento de atividades investigativas, pois este deve trabalhar de modo a despertar a autonomia e a cooperação entre os estudantes, proporcionando um clima de aprendizagem ativa e colaborativa.

Em seu trabalho Souza, Arruda, Almeida e Carvalho (2014) ressaltam que, para formar alunos críticos, a escola e os educadores devem oportunizar estratégias de ensino que possibilitem aos estudantes estimularem sua criatividade, tornando estes protagonistas no processo de ensino aprendizagem. Afirmam ainda que a aula prática é um meio eficaz para esta estimulação e que estas não necessitam de laboratórios para serem desenvolvidas, “...sendo possível que os alunos relacionem conceitos científicos com os conhecimentos adquiridos nas experiências do cotidiano, contextualizando os fenômenos que ocorrem na natureza com os acontecimentos que ocorrem à sua volta" (Souza et al., 2014, p. 395). Além disso, pode-se dizer que aulas realizadas em espaços não formais promovem um ensino menos fragmentado, proporcionando ao estudante uma visão global de mundo (Vieira, Bianconi \& Dias, 2005).

Uma das metodologias associadas ao ensino em espaços não formais, trata da realização de trilhas interpretativas. Este modelo pedagógico, também conhecido como trilhas guiadas ou trilhas autoguiadas, é utilizado com frequência em projetos desenvolvidos em ambientes naturais, de modo a proporcionar aos estudantes oportunidade de analisar os significados dos eventos observados no ambiente, bem como as características do mesmo (Zanin, 2006). Tabanez, Pádua, Souza, Cardoso \& Garrido (1997) demonstraram que o uso de trilhas interpretativas foi eficiente para o desenvolvimento de práticas de Educação Ambiental em atividades voltadas ao ensino médio e fundamental. Mette, Silva e Tomio (2010) utilizaram-se de trilha interpretativa em seu trabalho para verificar a percepção ambiental de estudantes do $5^{\circ}$ ano do ensino fundamental em Blumenal-SC e perceberam que após a realização da atividade prática, houve uma mudança significativa na concepção dos alunos sobre os elementos que compõe o ambiente, demonstrando a validade desta metodologia para o ensino de ecologia e práticas de educação ambiental.

Em trabalho desenvolvido por Silva et al. (2017), obteve-se ganho significativo na aprendizagem de ciências no ensino fundamental, através da utilização de trilha interpretativa para observação da avifauna de um trecho de mata ciliar em um córrego urbano. Vieira-da-Rocha e Molin (2010) relatam em seu trabalho sobre o potencial da utilização da observação de aves para desenvolvimento de atividades pedagógicas e afirmam que “...a observação de aves pode ser fácil e eficientemente utilizada como uma prática inovadora na disciplina de Ciências por reunir várias áreas do saber e permitir um resultado integrado" (Vieira-da-Rocha \& Molin, 2010, p. 47). Além disso, Santos e Praça (2015) verificaram em trabalho realizado com estudantes de ensino médio, que estes possuem poucas informações sobre aves locais e Santos e Silva (2012), ao analisar as informações sobre aves, em livros didáticos de biologia, observaram que alguns materiais não refletem a realidade.

Visto toda a necessidade de tornar o ensino de biologia mais atrativo e significativo aos estudantes, assim como proporcionar um maior conhecimento sobre a avifauna local, este trabalho teve o intuito validar a observação de aves em ambiente urbano, como um facilitador para o ensino de biologia.

\section{Metodologia}

\section{Área de estudo}

O presente estudo foi realizado no município de Juína, que fica localizado na porção noroeste do Estado de Mato Grosso, a $442 \mathrm{~m}$ de altitude, tendo como coordenadas geográficas: $11^{\circ} 22^{\prime} 42^{\prime \prime} \mathrm{S}$ de latitude e $58^{\circ} 44^{\prime} 28^{\prime \prime} \mathrm{W}$ de longitude. O município fica a $720 \mathrm{~km}$ da capital do estado, Cuiabá, e localiza-se no território mato-grossense pertencente a Amazônia Legal, com classificação climática Aw, segundo Koppen-Geiger (Alvares, Stape, Gonçalves \& Sparovek, 2013), apresentando clima 
tropical com estação seca de inverno. Possui uma extensão territorial de $26.190 \mathrm{~km}^{2}$ dos quais $60 \%$ pertencem a reservas indígenas e, segundo o censo populacional realizado pelo Instituto Brasileiro de Geografia e Estatística em 2010, o município contava com uma população de 39.255 pessoas, sendo a população estimada para o ano de 2020, por este mesmo órgão, em 41.101 pessoas. Ainda segundo o IBGE (2010), Juína possui uma população jovem com mais de 10 mil estudantes no ensino fundamental e médio, sendo considerado como município polo de referência em educação, saúde e comércio para os demais ao seu entorno.

Na região central do município, encontra-se a Escola Estadual Doutor Artur Antunes Maciel. Esta unidade atende cerca de 1000 estudantes e oferta exclusivamente o ensino médio, distribuídos nos três turnos, com turmas nas modalidades: ensino médio regular e ensino médio integrado ao ensino profissionalizante (EMIEP).

Próximo a esta unidade escolar, existe um parque municipal denominado de Parque Lagoa da Garça. Antes da criação do município esta era uma área de mata, com um pequeno córrego ao centro, porém com a urbanização e consequentemente a elevação e a pavimentação das vias, as águas foram represadas, formando um lago, que popularmente ganhou o nome de Lagoa da Garça. No ano de 2016, o governo municipal readequou as vias de acesso as margens da lagoa, construindo pistas de caminhada e academias públicas de primeira e terceira idade, assim o Parque Lagoa da Garça tornou-se um local tradicional do município de Juína, sendo muito utilizado pela população como local de lazer, esporte e descanso. Este foi o local escolhido para a realização da trilha interpretativa, com os estudantes atores desta pesquisa.

\section{Aula investigativa e trilha interpretativa}

A presente proposta foi desenvolvida com 20 estudantes, pertencentes a turma do $2^{\circ}$ ano "B" do Ensino Médio Técnico em Administração da Escola Estadual Dr. Artur Antunes Maciel, localizada no município de Juína-MT. Esta turma foi selecionada, por ser a etapa prevista para o ensino de zoologia, segundo o currículo adotado pela unidade escolar e por ser de lotação desta pesquisadora como professora regente de biologia.

Este trabalho passou pelo crivo do Comitê de ética em Pesquisa/ UNEMAT e teve sua autorização através do parecer no 3.264.419. Os estudantes tiveram a participação voluntária e o estudo só teve início após o preenchimento do Termo de Consentimento Livre e Esclarecido e do Termo de Assentimento, juntamente a seus pais e/ou responsáveis.

Assim, foi elaborado uma sequência didática com a utilização de abordagem investigativa sobre a composição da avifauna do município, tendo como culminância a realização de trilha interpretativa no Parque Lagoa da Garça em Juína-MT. A proposta didática foi encaminhada a coordenação pedagógica e executada apenas após aprovação da mesma.

A sequência didática teve duração de 11 horas/aulas, divididas nas três etapas descritas a seguir:

- Primeira etapa (4h): Introdução a temática e exposição da situação problema.

Esta etapa foi realizada em dois dias, um a cada semana (12/11/2019 e 19/11/2019), com duas horas/aulas cada. No dia doze de novembro de dois mil e dezenove (2h), foi entregue aos estudantes um questionário, denominado de pré-teste, contendo 8 questões abertas, que teve como objetivo verificar os conhecimentos prévios a respeito da classe zoológica aves e verificar a percepção que os discentes têm da avifauna local. Após responderem o questionário, os estudantes realizaram a leitura do livro didático correspondente a classe zoológica em estudo, observando atentamente as aves citadas no texto, nominalmente ou por fotos. Vale ressaltar que através do Programa Nacional do Livro e Material Didático (PNLD), a Escola Dr. Artur adotou como livros didáticos para o triênio 2018/2019/2020, aqueles pertencentes a coleção Biologia Moderna, da editora Moderna, escritos José Mariano Amabis e Gilberto Rodrigues Martho.

O livro didático em questão, trata da classe aves e suas características em um pequeno texto, que ocupa meia página, trazendo citação de três aves: uma de maneira genérica ("uma espécie de beija-flor") e duas aves não pertencentes a fauna 
brasileira: avestruz (Struthio camelus) e cegonha-branca (Ciconia ciconia). Deste modo, ao realizarem a leitura do texto e perceberem a não ocorrência das espécies citadas no município de residência, os estudantes acabaram por indagar quais seriam as espécies locais que poderiam substituir aquelas informadas no texto. Assim, aproveitou-se este momento para lançar a pergunta norteadora: Como pode-se saber quais aves compõem a avifauna do município de Juína?

Com base no questionamento feito, o grupo de estudante realizou debates, chegando a duas hipóteses para a solução da situação problema proposta: em primeiro lugar, deveriam verificar a existência de uma lista de aves próprias da região, realizando buscas junto a banco de dados online e instituições de ensino superior da cidade e, em segundo lugar, no caso de não existir esta informação para a localidade, verificar quais métodos poderiam ser utilizados por eles para a construção desta listagem. Após as proposições realizadas pelos discentes, estes foram divididos em grupos e as equipes foram instruídas a realizar pesquisas a fim de validar as hipóteses propostas anteriormente. Para tanto, foi disponibilizado o acesso a rede wifi, laboratório de informática e biblioteca escolar.

$\mathrm{Na}$ segunda semana (2h) os estudantes realizaram a socialização dos dados obtidos pela pesquisa e passaram a sistematizar a metodologia a ser adotada para o levantamento de avifauna local, preparando-se para a realização de uma trilha interpretativa utilizando a pista de caminhada do Parque Lagoa da Garça.

- Segunda etapa (5h): trilha interpretativa

Esta etapa foi realizada durante o período matutino do dia 29/11/2019 das 06:00 às 11:00 horas. A trilha interpretativa teve o objetivo de levar os estudantes a observarem a avifauna local, destacando a relação entre hábitat e diversidade biológica, além de discutir situações problemas relacionadas a conservação do ambiente em estudo. Os estudantes se reuniram na área denominada de "quiosque" localizada em área verde disposta em frente ao Parque Lagoa da Garça (figura 8), as 06:00 da manhã, e lá foram organizados em grupos, onde cada membro assumiu a responsabilidade por uma função, sendo ela de observação, conferência ou registro de dados. Esta área é utilizada pela prefeitura municipal para a realização de eventos propostos pela Secretaria Municipal de Cultura e, portanto, conta com um amplo espaço aberto, com mesas e bancos sob a sombra das árvores e um quiosque com área de cozinha.

Após a organização e distribuição das funções, a turma foi encaminhada a pista pavimentada ao redor da Lagoa da Garça, onde realizaram caminhada lenta, com paradas em pontos estratégicos para registro das aves pousadas ou em voo, assim como realizar registro das condições ambientas da área de estudo e das relações desenvolvidas entre aves e o ambiente. Cada grupo de estudantes dispunha de uma máquina fotográfica semi-profissional para registro das espécies de aves avistadas e posterior identificação por comparação a guias de campo. Todo este processo foi coordenado pela professora titular, com o auxílio e colaboração do diretor escolar e mais dois professores.

Após a coleta de dados, os estudantes foram reunidos novamente na área verde do quiosque, onde receberam lanche e posteriormente realizaram a organização dos dados coletados, discussão e debate entre os grupos e sistematização de um relatório final coletivo.

- Terceira etapa (2h): Aplicação de questionário pós-teste.

No dia 03/12/2019, os estudantes receberam um questionário denominado de pós-teste, contendo 10 questões abertas, que versavam sobre as características gerais da classe zoológica aves e também sobre a percepção dos estudantes sobre metodologia aplicada durante a aula investigativa e trilha interpretativa. 


\section{Resultados e Discussão}

Esta etapa da pesquisa foi desenvolvida com 20 estudantes do segundo ano do ensino médio com ensino técnico integrado em Administração, com média de 16,4 anos de idade, sendo 30\% do sexo masculino e $70 \%$ do sexo feminino. Embora a unidade escolar esteja localizada em área central da cidade, os participantes desta pesquisa residem em onze bairros distintos (apenas um reside no mesmo bairro da unidade escolar), demonstrando assim a heterogeneidade amostral.

\section{Desenvolvimento da sequência didática}

A realização da primeira etapa da execução da sequência didática ocorrida no dia 12/11/2019, aconteceu em ambiente formal de ensino, nas dependências da Escola Estadual Dr. Artur Antunes Maciel. Após leitura do livro e proposição da pergunta norteadora pela professora, os estudantes mostraram-se muito participativos, realizando debate e suscitando temáticas que gostariam de saber sobre as aves, além de construírem coletivamente as hipóteses para o questionamento apresentado. Duas foram as hipóteses apresentadas pelos estudantes: 1- Buscar a existência de uma lista de aves da região, junto a banco de dados on-line e instituições de ensino superior da cidade; e 2- Na inexistência desta lista, construir eles próprios esta listagem.

No dia 19/11/2020, ao observaram a inexistência de uma listagem de espécies de aves própria do município, os estudantes optaram então pela realização de um levantamento amostral. Neste momento a professora sugeriu a execução de uma trilha interpretativa, na pista de caminhada do Parque Lagoa da Garça. Os estudantes se mostraram muito receptivos a proposta e iniciaram a elaboração dos passos a serem adotados durante a prática, pensando no método a ser aplicado, materiais necessários e regras de comportamento a serem mantidas pelo grupo durante a execução da trilha interpretativa (Figura 1). Para tanto, os estudantes tiveram acesso a imagem aérea do parque obtida através do Google Earth, guias de campo com lista de aves do Brasil e acesso à internet para pesquisas diversas.

Figura 1. Observação da imagem aérea do Parque Lagoa da Garça para elaboração da metodologia a ser aplicada durante a realização da trilha interpretativa.

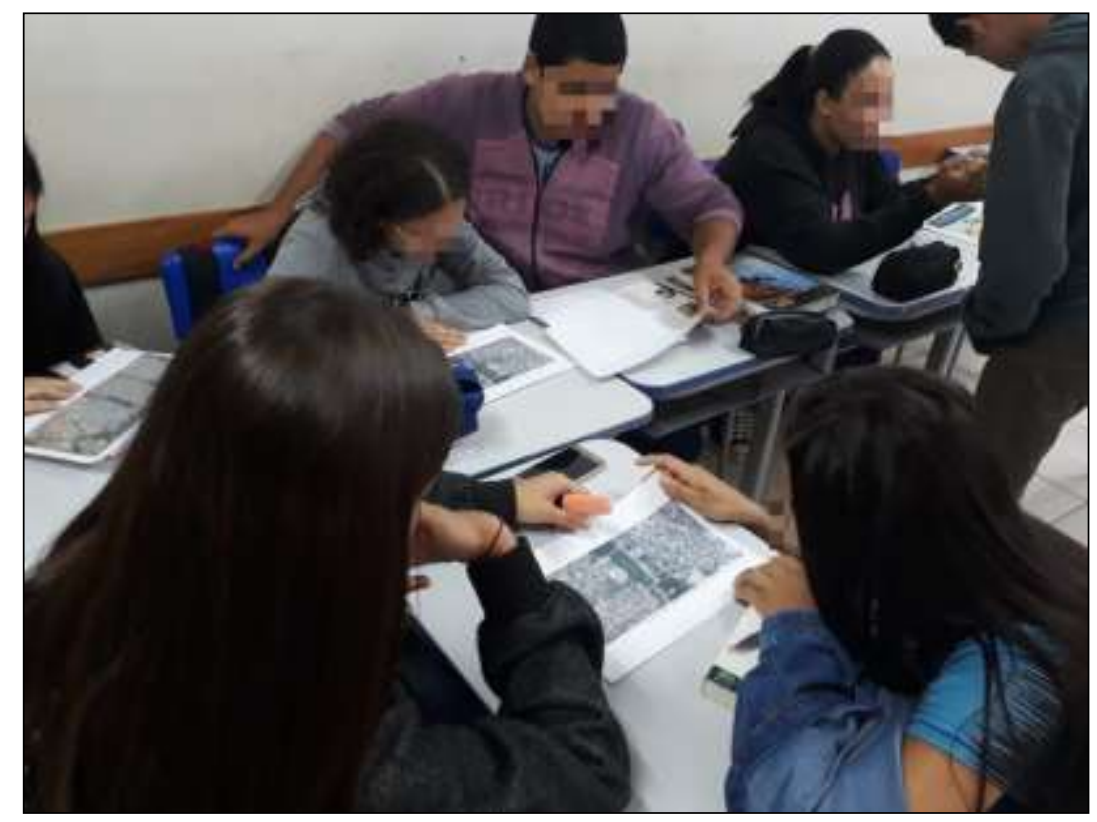

Fonte: Autores. 
Há de se destacar, o protagonismo dos estudantes nesta fase, que se empenharam na busca de informações a respeito da temática proposta, mobilizando diferentes saberes, desenvolvendo o espírito de colaboração para a resolução de problemas e promovendo a aprendizagem colaborativa. Segundo Diesel, Baldez e Martins (2017) estes momentos de troca de experiências e de interação constante com os colegas e professores, a fim de tomar decisão conjunta, leva os estudantes a constantemente refletir sobre uma situação, a emitir opinião e produzir argumentos. Cleophas (2016) afirma que esta interação é uma das grandes vantagens do ensino por investigação, uma vez que a interação social favorece a argumentação e contribuí para a solução de problemas de modo coletivo, mobilizando conhecimentos previamente adquiridos pelos estudantes.

No dia 29/11/2019 as 6:00 da manhã, estudantes e professores reuniram-se na área do quiosque municipal em frente ao Parque Lagoa da Garça para a realização da trilha interpretativa. No primeiro momento as normas de comportamento e metodologia a serem aplicadas foram relembradas pelo grupo, para posteriormente seguir para a trilha. Durante a visita guiada os estudantes se organizaram em cinco grupos compostos por quatro integrantes (um responsável pelo registro fotográfico, outro responsável pelo registro dos dados em planilha e outros dois responsáveis pela observação dos espécimes presentes, condições do ambiente de estudo e registro das interações ecológicas observadas a campo).

Durante a realização da visita guiada, os estudantes puderam observar as aves locais e as interações destas com o ambiente, relacionando a composição da avifauna com a vegetação presente nos pontos amostrais e ainda com a conservação ambiental do parque. Puderam ainda, desenvolver a capacidade de trabalhar em equipe e o senso de responsabilidade ambiental. Como pode-se observar na Figura 2, a metodologia empregada durante a trilha interpretativa, manteve os estudantes motivados e envolvidos com a dinâmica proposta.

Figura 2. Estudantes observando e registrando as aves do Parque Lagoa da Garça durante trilha interpretativa, em Juína-MT.

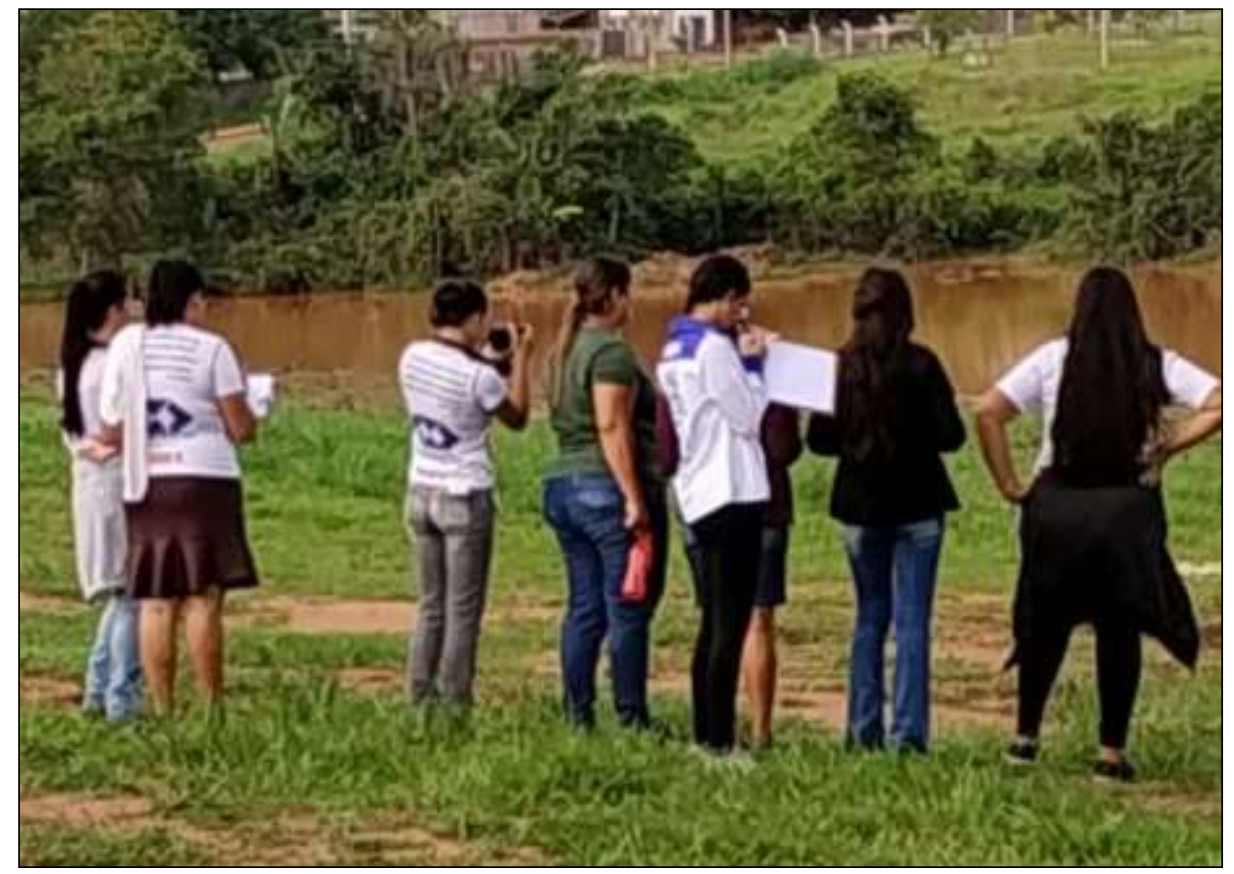

Fonte: Autores.

Ao final da trilha interpretativa, os estudantes retornaram ao quiosque municipal, reuniram-se para organizar os dados e elaborar um relatório geral da atividade (Figura 3). 
Figura 3. Estudantes realizando a organização dos dados e construção do relatório geral final.

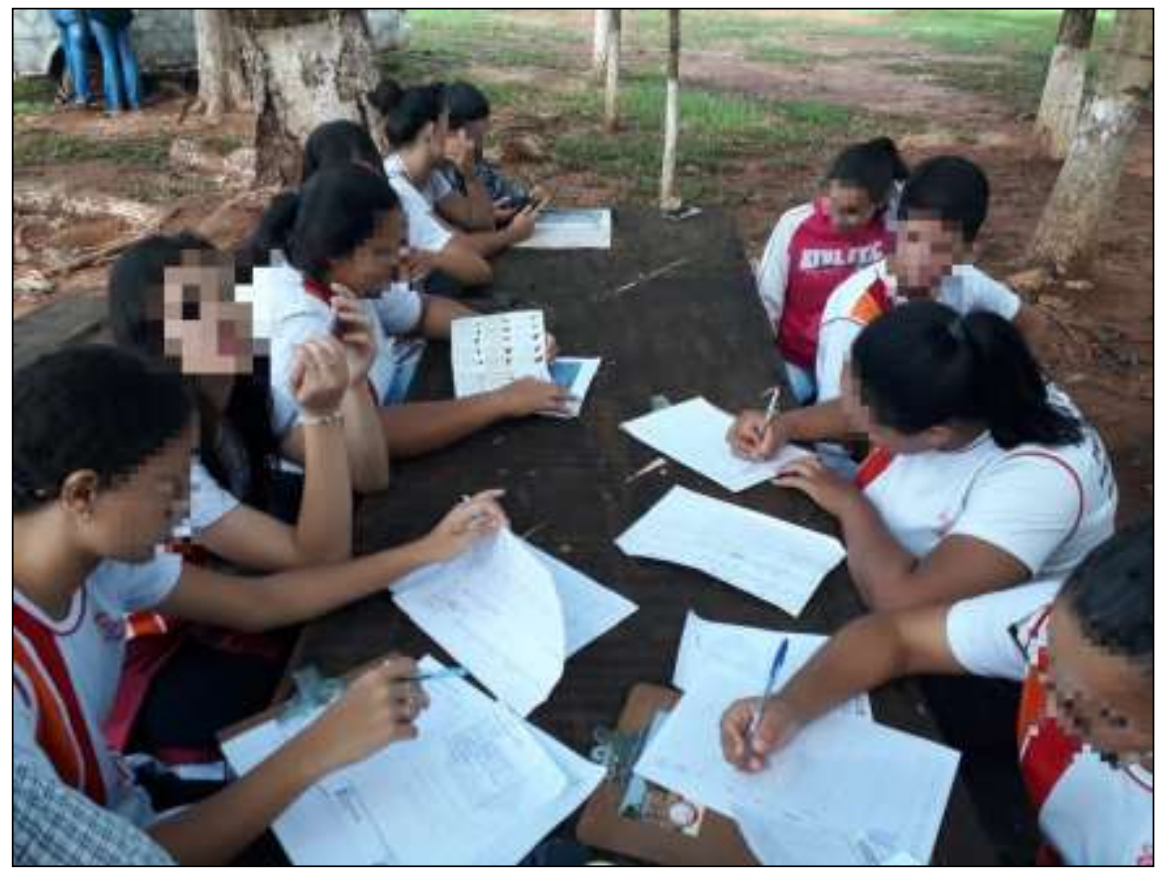

Fonte: Autores.

Durante a realização da trilha interpretativa os estudantes puderam realizar 204 avistamentos, sendo identificadas 36 espécies (equivalentes a 35,7\% do total de aves registradas para a localidade), pertencentes a 16 famílias (48,5\% das famílias de ocorrência no parque). A família Thraupidae e Psittacidae foram as mais representativas com 8 e 6 espécies, respectivamente. Importante ressaltar que, por ser a primeira vez que estes estudantes se puseram a observar aves e tentar identifica-las e ainda, com a movimentação e barulho ocasionado pela aglomeração de estudantes e professores - o que pode ter afugentado algumas espécies mais sensíveis a presença humana - estes dados de coleta são considerados satisfatórios.

Durante a realização da trilha interpretativa, as características de cada espécie de ave avistada e a relação destas com o ambiente em que ocorreu a observação foram trabalhadas com os estudantes, relacionando-as com as ações antrópicas observadas em cada ponto amostral. Os estudantes puderam também, observar algumas aves durante o processo de alimentação e assim, comparar formatos dos bicos e o tipo de alimento ingerido, relacionando ainda o comportamento alimentar com as funções ecológicas desempenhadas pelas aves como: controle de insetos, dispersão de sementes, polinização, entre outros.

O descarte irregular de material não biodegradável nas margens e na lâmina d'água da lagoa também foi um ponto observado e bastante comentado pelos estudantes durante a realização da trilha interpretativa. Esta capacidade de perceber a poluição do ambiente estudado é um ponto muito positivo, pois a tomada de consciência favorece hábitos mais saudáveis ao ambiente e colabora para ações que contribuem para a conservação da localidade, uma vez que:

A vivência cotidiana muitas vezes mascara circunstâncias visíveis, mas não perceptíveis. Mesmo contemplando casos de agressões ao ambiente, os hábitos cotidianos concorrem para que o morador urbano não reflita sobre as conseqüências de tais hábitos, mesmo quando possui informações a esse respeito (Mucelin \& Bellini, 2008, p. 113).

\section{Análise dos questionários}

Para averiguação do impacto pedagógico da observação de aves no ensino de biologia, foram utilizados dois tipos de questionários com os estudantes: o primeiro (pré-teste) foi aplicado logo no início da sequência didática, após a assinatura dos 
termos de consentimento e assentimento, e outro (pós-teste) foi aplicado aos estudantes na aula seguinte a realização da trilha interpretativa no parque 'Lagoa da Garça". Ambos foram respondidos pelos vinte alunos que compunham a turma.

O primeiro questionário era composto por oito perguntas abertas e visava averiguar o conhecimento prévio dos estudantes sobre as principais características da classe aves e a relação da diversidade destas com as ações do ser humano. Já o segundo questionário era composto por dez questões, todas abertas, sendo que as cinco primeiras eram as mesmas do primeiro questionário anterior, o que possibilitou verificar o avanço nas construções cognitivas a respeito do assunto estudado durante a prática investigativa em ambiente não formal. Já as cinco questões posteriores versavam sobre a percepção dos estudantes quanto a metodologia aplicada.

\section{Questões de 01 a 05 (comuns a ambos questionários)}

Na primeira pergunta, os estudantes foram questionados sobre as características gerais da classe aves. Observando as respostas do pré e pós teste, nota-se que as características mais lembradas foram a capacidade de voar, presença de bico e corpo coberto por penas em ambos os questionários, no entanto observa-se que após a realização da aula investigativa, há uma queda no número de citações do voo como uma característica geral da classe e essa passa a ser reconhecida como pertencente a um grupo grande, porém não a todas as espécies de aves. O Quadro 1 retrata essa mudança semântica na estruturação das respostas construídas no pré e pós teste, trazendo como exemplificação a fala de três estudantes.

Quadro 1. Mudança na estruturação semântica das respostas dos estudantes entre pré e pós teste, quanto as características gerais das aves.

\begin{tabular}{|l|l|l|}
\hline \multirow{2}{*}{ Estudantes } & \multicolumn{1}{|c|}{ Citações do voo como característica das aves } \\
\cline { 2 - 3 } & \multicolumn{1}{|c|}{ Pré teste } & \multicolumn{1}{c|}{ Pós-teste } \\
\hline K.K.R.A. & $\begin{array}{l}\text { "As aves tem penas, voam, bicam } \\
\text { e andam em bando." }\end{array}$ & $\begin{array}{l}\text { "As aves possuem penas (corpo revestido), possuem } \\
\text { asas, grande parte conseguem voar completamente ou } \\
\text { voos curtos..." }\end{array}$ \\
P.F.F. & $\begin{array}{l}\text { "Elas tem penas, se alimentam pelo } \\
\text { bico, voam, ..." }\end{array}$ & "Tem penas; algumas voam..." \\
\hline R.D.S. & "Elas voam; Voam em bando; ..." & $\begin{array}{l}\text { "Uma das principais características do grupo é: eles } \\
\text { voam, mesmo sendo galinha, por exemplo a galinha } \\
\text { d'água elas apenas dão voos curtos..." }\end{array}$ \\
\hline
\end{tabular}

Fonte: Autores.

Estas mudanças de percepção e afirmações em dados já conhecidos, demonstram a importância do desenvolvimento de atividades pedagógicas em ambientes não formais de ensino, pois durante uma atividade de campo é possível utilizar-se de diversas situações didáticas que promovam a contextualização e a interdisciplinaridade, tornando a aprendizagem de conceitos científicos interessante e versátil, possibilitando que estudantes coloquem em prática conhecimentos já adquiridos porém esquecidos devido ao distanciamento de sua práxis diária (Cleophas, 2016). 
Gráfico 2. Características da classe aves segundo os estudantes, antes e após a realização da sequência didática investigativa.

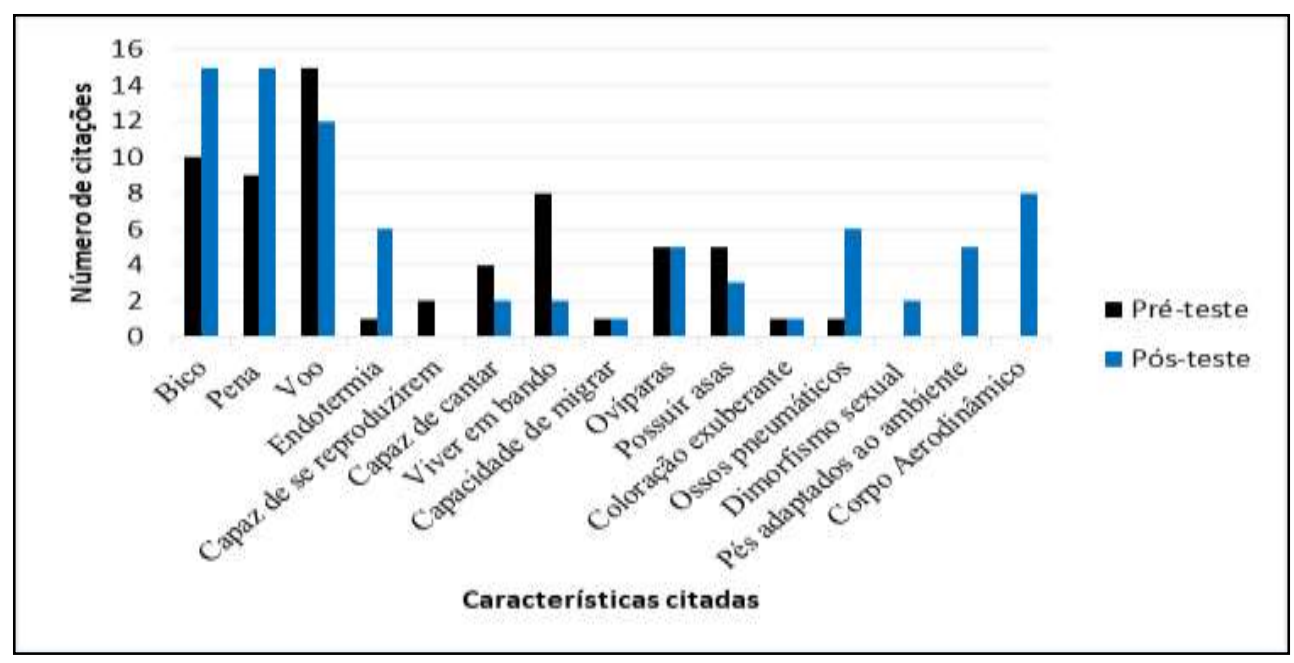

Fonte: Autores.

Ainda para a questão 1, no questionário pós-teste, observou-se o surgimento de características não citadas anteriormente (dimorfismo sexual, pés adaptados ao ambiente e corpo aerodinâmico), com termos de uso próprio da linguagem científica (Gráfico 2), demonstrando o enriquecimento do vocabulário científico dos estudantes durante o desenvolvimento da aula investigativa.

A segunda questão abordou o conhecimento dos estudantes sobre a alimentação das aves e as repostas de ambos os testes são apresentadas no Gráfico 3. Pode-se observar que para responder o pré-teste os estudantes basearam-se em suas vivências pessoais com a classe zoológica em estudo e assim, embora insetos seja mais citado como fonte de alimentação das aves, respostas indicando alimentos fornecidos a aves domésticas ou de cativeiro como ração, quirela, alpiste e milho, foram bastante ocorrentes. Já durante o pós-teste, observa-se aumento na diversidade de respostas, sendo citado aves que predam ovos, larvas e crustáceos e ainda as que se alimentam de néctar ou são granívoras ou onívoras.

Gráfico 3. Composição da alimentação das aves segundo os estudantes, durante pré-teste e pós-teste.

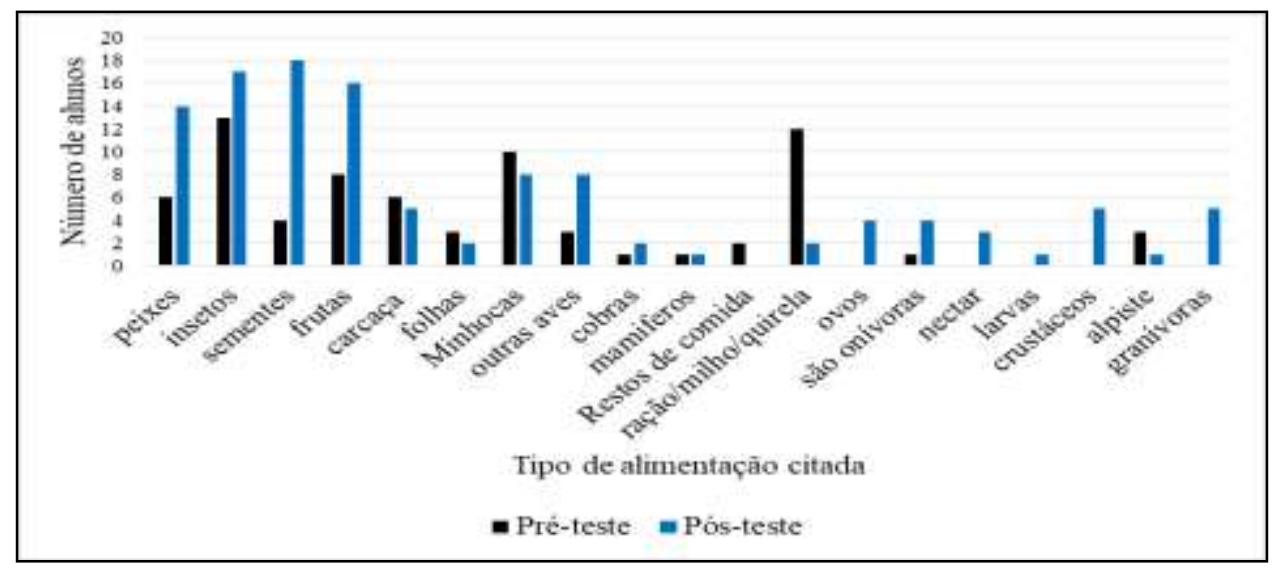

Fonte: Autores.

Ao analisar a construção das respostas de pré-teste e pós-teste para a pergunta 2, pode-se observar uma clara evolução na estrutura sintática e semântica das respostas, onde a princípio os estudantes se puseram a construir meras listas e conforme 
foram se apropriando do conhecimento técnico e da linguagem própria do meio científico, suas respostas passam a ser mais argumentativas. Abaixo foi reproduzido a resposta de uma estudante durante pré e pós teste, onde torna-se possível a observação desta evolução.

Pergunta 2: $\mathrm{O}$ que as aves comem?

“Minhoca; Frutas; Peixes.” (R.D.S. - Questionário pré-teste)

"Algumas aves são generalistas -que comem de tudo- outras são insetívoras, outras são granívoras e outras piscívoras. Nós vimos o Suiriri, no qual observamos o bico e é bico de ave insetívora, e vimos a Pipira Vermelha no qual o bico dela é bico de ave granívora." (R.D.S. - Questionário pós-teste)

Neste exemplo podemos averiguar o desenvolvimento do vocabulário científico da estudante, que além de apresentar as definições de modo correto, recorre ao uso de exemplos para justificar sua resposta. Lemke (1997) afirma que as respostas dadas pelos estudantes adquirem cada vez mais coerência e vão tornando-se cada vez mais complexas e coesas conforme estes se apropriam de novos elementos, e ainda que a alfabetização científica se dá justamente quando os estudantes são capazes de utilizar a linguagem própria do meio científico, não apenas como uma lista de termos técnicos, mas tornam-se capazes de utilizar esses termos relacionando-os uns com os outros em uma variedade de contextos diferentes.

Na terceira questão, os estudantes foram indagados quanto a importância das aves para o ambiente e as respostas são demonstradas no Gráfico 4. Pode-se observar que no resultado do pré-teste, cinco estudantes declararam não ter conhecimento a respeito da importância dessa classe para o ambiente e ainda, outros 6 estudantes relacionaram a importância das aves com o fornecimento comercial de carne e ovos. Observa-se que após a execução da aula investigativa e da trilha interpretativa os estudantes passam a ter maior consciência da importância das aves para o meio ambiente como um todo, zerando o número de estudantes sem conhecimento sobre o assunto.

Gráfico 4. Importância das aves para o ambiente segundo a visão dos estudantes.

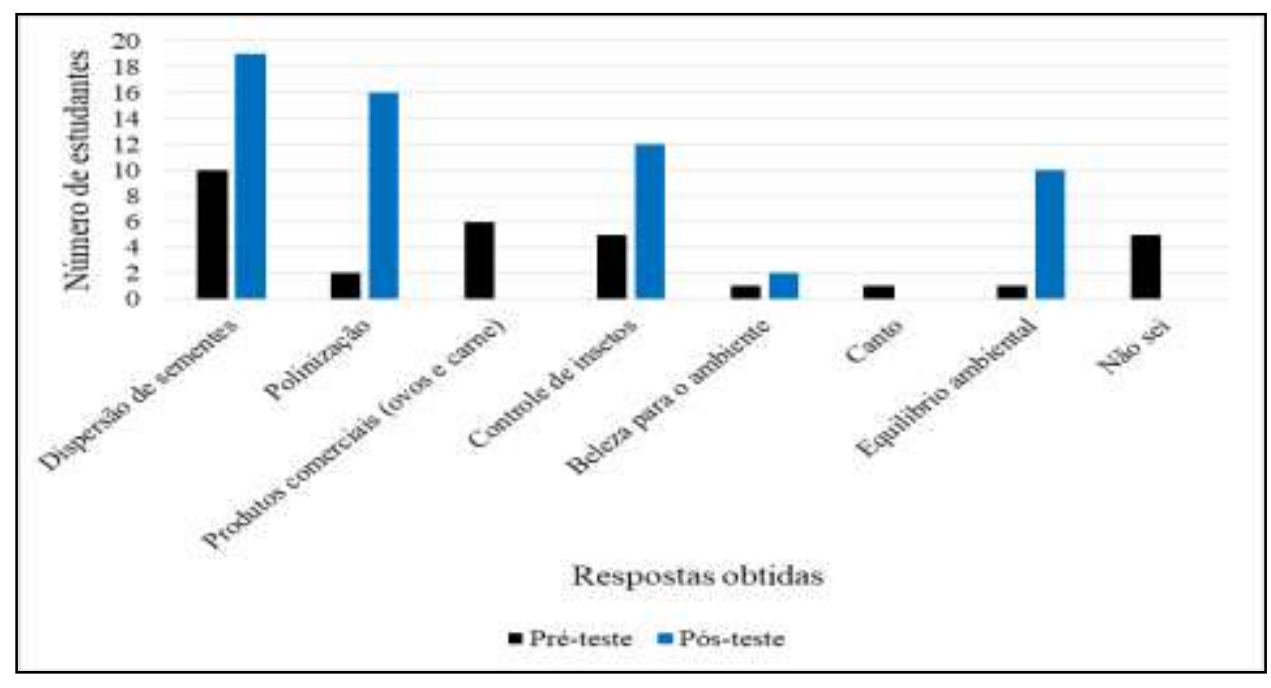

Fonte: Autores. 
A pergunta de número quatro, questionou os estudantes sobre a função dos sons produzidos pelas aves (Gráfico 5). Analisando as respostas dadas, pode-se observar que antes da realização da aula investigativa e da trilha interpretativa os sons produzidos pelas aves eram vistos como meio de comunicação desses seres, analogicamente a fala nos humanos. Já após a realização das atividades pedagógicas, funções como: atrair parceiro para a reprodução e demarcação de território, passaram a ser as funções mais atribuída ao ato de vocalização.

Gráfico 5. Função dos sons produzidos pelas aves segundo os estudantes.

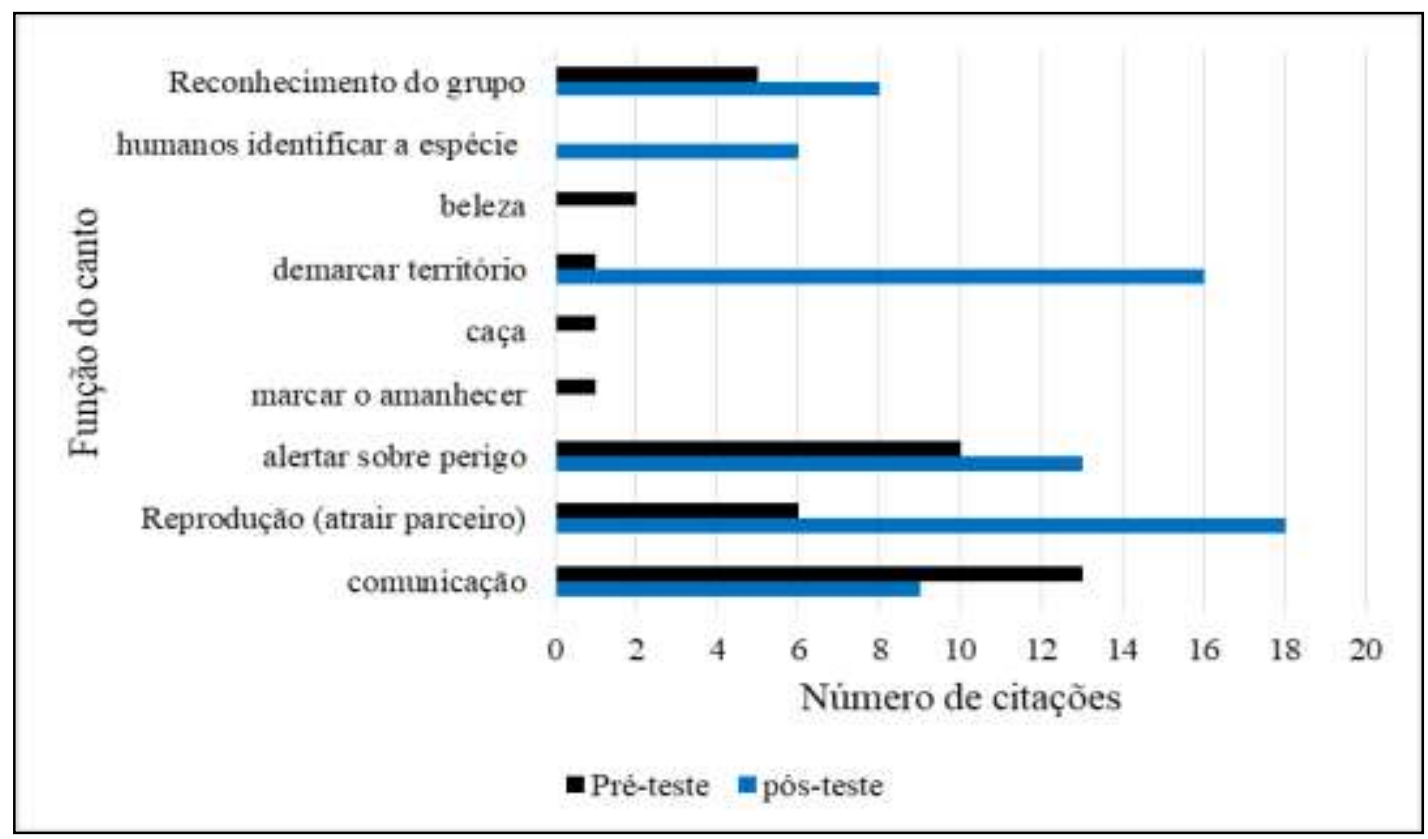

Fonte: Autores.

Através da questão cinco, buscou-se saber a opinião dos estudantes sobre a função das penas para as aves. Analisando-se as respostas, nota-se que o voo é a função mais citada em ambos os questionários (Gráfico 6), no entanto observa-se que nas respostas do pós-teste, os estudantes passam a ver o isolamento térmico como uma função importante desempenhada pelas penas.

Interessante chamar a atenção neste momento para o enriquecimento de saberes de modo interdisciplinar e não fragmentado ocorrido durante a prática pedagógica proposta por esta pesquisa. Observem que, durante o pré-teste, dez estudantes relatam que as penas "produzem calor" para o corpo das aves, incorrendo em um erro conceitual da área da física, enquanto no pós-teste afirmam que as penas "servem como isolante térmico". Essa clara mudança conceitual, nos mostra que aulas que aliam o método investigativo à ambientes não formais contribuem para um ensino menos fragmentado, como disse Vieira et al (2005, p. 23) “Afinal, o ensino não deveria ser fragmentado já que a realidade não é fragmentada." 
Gráfico 6. Função das penas das aves segundo os estudantes.

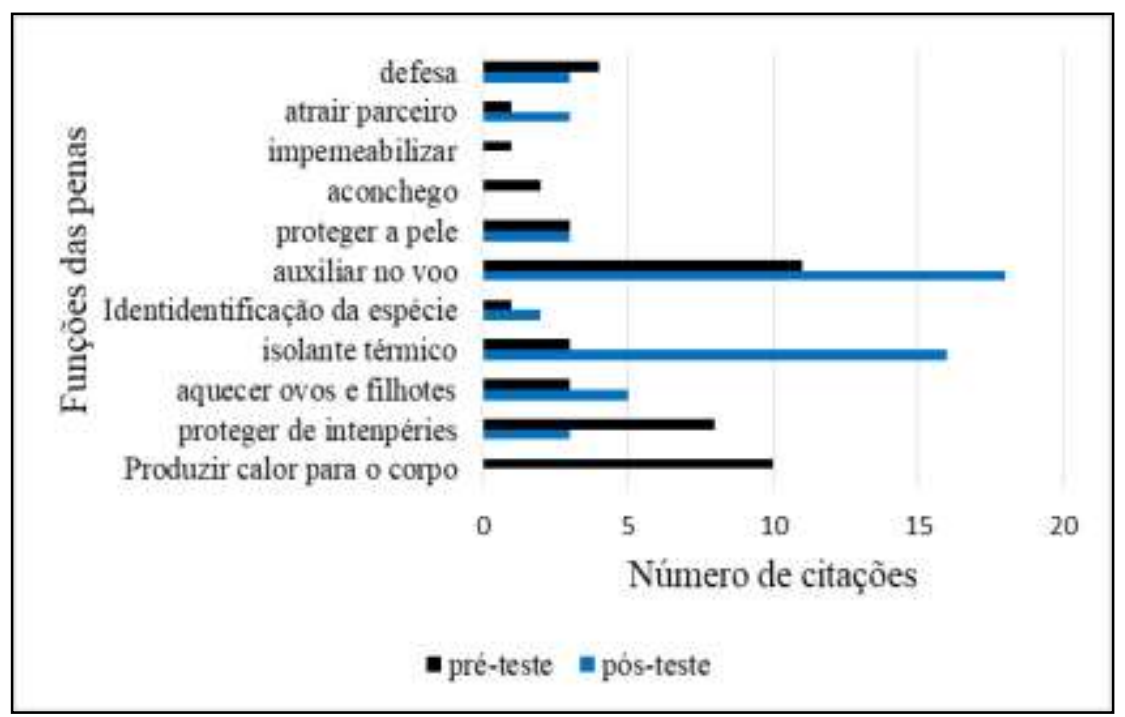

Fonte: Autores.

\section{Questões de 06 a 08 do pré-teste}

Nesta seção serão apresentados os resultados referentes as questões de números 06, 07 e 08 do questionário pré-teste, aplicado aos estudantes antes da realização da aula investigativa e trilha interpretativa no Parque Lagoa da Garça, em JuínaMT.

Na questão 06 foi solicitado aos estudantes que escrevessem quais aves eles já haviam visualizado no município de Juína-MT, visando assim, observar o conhecimento sobre a avifauna local. Ao todo foram obtidas 192 citações, relacionando 36 etnoespécies de aves, gerando uma média de 9,6 citações por estudante. Estes dados corroboram com aqueles levantados por Santos e Praça (2015), onde observaram média de 7,8 menções de aves por estudantes, sendo esta uma taxa considerada baixa pelos autores visto a riqueza de espécies encontradas no Brasil. Outro fator que merece atenção, foi a citação de morcego como exemplo de ave por três estudantes, reforçando a necessidade do ensino das características gerais desta classe zoológica para o ensino médio.

Com o texto "Imagine que um turista estrangeiro venha passar um tempo em Juína para observar pássaros e te peça indicação de um lugar dentro da cidade para tal atividade. Qual local você indicaria?", a sétima questão visou verificar se os estudantes, antes da realização da aula investigativa e da trilha interpretativa, consideravam o Parque Lagoa da Garça como um local onde se era possível a observação de aves. Através do resultado, pode-se observar que apenas $35 \%$ dos estudantes identificavam o local como um ponto possível de observação. Este dado demonstra que aulas elaboradas utilizando espaços urbanos, como espaços não formais de ensino, podem corroborar para práticas de conservação ambiental, afinal não se pode conservar aquilo que se desconhece.

$\mathrm{Na}$ questão de número oito, ao perguntar quais ações humanas interferem na diversidade de aves no Brasil, o desmatamento foi o mais citado (12), seguido por caça (6) e tráfico de aves (6). Outros três estudantes afirmaram desconhecer ações humanas que interferem diretamente na diversidade de aves de um local.

\section{Questões de 06 a 10 do pós-teste}

Neste tópico estão dispostos os dados referentes as questões de 06 a 10 do questionário pós-teste que se referem a percepção dos estudantes sobre a prática pedagógica desenvolvida. 
Na questão de número 06, os estudantes foram inquiridos sobre as aves avistadas na Lagoa da Garça durante a realização da trilha interpretativa. Através das respostas pode-se perceber que, mesmo passada uma semana, os estudantes foram capazes de citar 31 espécies das 38 que foram avistadas a campo. Em média, cada estudante mencionou 12,45 aves que, se comparar esses dados com as aves já conhecidas por eles obtidas pelo questionário pré-teste (questão 06) e debatido no subtópico anterior, percebe-se um acréscimo de $29,7 \%$ de espécies conhecidas. Estes dados mostram a importância de aulas em ambientes não formais na tomada de conhecimento da avifauna local pelos estudantes, fato observado também por Hanzen, Tavares e Gimenes (2015).

Quanto a percepção sobre a prática pedagógica desenvolvida em sala de aula, abordada na questão sete, dezessete estudantes classificaram como boa ou ótima, dois como regular e um não respondeu. Entre as qualidades do método citadas pelos estudantes, destacam-se o desenvolvimento da autonomia e do trabalho em equipe:

"Foi muito bom, foi uma experiência ótima pois cada aluno tinha uma função importante, cada aluno teve que se esforçar para aprender sobre o conteúdo e depois expor no debate." (Y.L.S.)

"Ótimo método pois além do conhecimento que tivemos pesquisando, nos traz um senso de responsabilidade maior em aprender." (K.K.R.A)

"Foi uma atividade que mostrou a importância de trabalhar em grupo..." (A.C.A.C.)

Entre os pontos fracos da metodologia aplicada em sala, dois estudantes apontaram a não participação de por parte de alguns colegas.

"Muitos alunos se ajudaram e se empenharam, mas alguns ficaram na banheira, deixando a desejar. Mas na hora da aula de campo todos participaram.” (J.C.B.F.S.)

“Nem todos os alunos se empenharam da mesma maneira, ..." (A.C.A.C.)

A questão de número 08 instigou os estudantes a relatarem o sentimento que tiveram durante a realização da trilha interpretativa. Todos os estudantes declararam sentimentos positivos com a realização desta prática e apenas dois alunos citaram o cansaço devido a caminhada, como ponto negativo. Uma das situações observadas pelos estudantes e bastante citada, foi o aspecto interdisciplinar da aprendizagem durante a realização desta prática pedagógica:

“...Muito interessante essas aulas de campo, aborda diversos temas, não apenas sobre as aves, mas muito mais." (P.F.F)

"Foi ótimo. Aprendi muito, sobre muitas coisas que nunca tinha parado pra observar, muito mais que biologia" (D.C.N.B)

Além dos aspectos pedagógicos, aulas realizadas em ambientes naturais proporcionam mudanças em aspectos comportamentais dos estudantes, contribuindo para maior interação entre os estudantes. 
“Me senti livre!" (P.F.F.)

"Me senti mais solto em um ambiente mais agradável. Em sala sou mais tímido. Penso que aulas assim auxiliam mais que em sala" (E.G.P.S)

Algumas falas, refletem o encantamento que a classe aves causa no ser humano, despertando nos estudantes curiosidade e desejo em aprender, corroborando o pensamento de Costa (2007) e Hanzen, Tavares e Gimenes (2015):

"Me senti grata, foi uma experiência incrivel onde escutar o canto dos pássaros era tranquilizante." (A.C.A.C.)

"Me senti muito bem, pois o contato com a natureza, conhecer os pássaros, nos traz paz e harmonia. O canto fez com que ficássemos animados e curiosos para aprender mais sobre esses seres que temos ao nosso redor.” (K.K.R.A)

Na questão de número 09 , ao serem questionados se gostariam de ter mais aulas como aquelas desenvolvidas durante o projeto, $90 \%$ dos estudantes deram respostas positivas. Um estudante não respondeu e apenas um respondeu negativamente, atrelando sua resposta ao fato de possuir problemas de saúde que o deixara muito cansado durante o desenvolvimento da trilha.

A décima questão do pós-teste, informava aos estudantes que seria construído um material que auxiliasse outras pessoas a aprender sobre as aves da Lagoa da Garça e solicitava dicas, de maneira que citassem quais as informações que eles acreditavam ser importantes e necessárias para constar neste material. Assim $85 \%$ dos estudantes disseram que seria interessante a construção de um guia contendo informações sobre as espécies encontradas no Parque Lagoa da Garça, apresentando as características gerais da classe, além de dicas de materiais e comportamentos necessários para a observação de aves.

"Acho que deveria ter um guia relatando as aves da nossa região e um mapa mostrando onde podem ser encontradas na lagoa." (E.G.P.S)

"Um guia com foto das aves, mapa dos pontos e o que fazer quando encontrar a ave". ( J.C.B.F.S.)

As informações e anseios dos estudantes observados através das respostas dadas a esta questão, serviram de base para a construção de um livro paradidático que aborda a observação de aves no Parque Lagoa da Garça, trazendo um guia de identificação das espécies ocorrentes na localidade, bem como diversos aspectos biológicos ligados a essa classe zoológica.

\section{Considerações Finais}

O presente trabalho almejou evidenciar a observação de aves no Parque Lagoa da Garça em Juína-MT, como uma ferramenta válida para o ensino de biologia. Desta forma, buscando conhecer a área de estudo e toda sua potencialidade, foi realizado um levantamento das aves ocorrentes na área do parque durante um ano, período este em que foi possível identificar 101 espécies, pertencentes a 19 ordens e 33 famílias, sendo este um número bem expressivo em se tratando de uma área urbana com pouca vegetação ciliar.

De posse da listagem de espécies de aves encontradas na área, foi possível elaborar uma sequência didática investigativa que incluiu a realização de uma trilha interpretativa com os estudantes aliando assim, teoria e prática. Com o intuito de se verificar o conhecimento prévio dos estudantes sobre aves e compreender o modo como a aprendizagem ocorreu 
durante a prática didática proposta, antes e posterior a execução do planejamento didático, os estudantes responderam questionários, denominados de pré-teste e pós-teste, que auxiliaram na verificação da validade do método didático empregado.

Através das respostas dos estudantes, pode-se verificar que a atividade proposta possibilitou a eles conhecer mais sobre as espécies de aves locais, observando a importância ecológica desta classe e a estreita relação da diversidade deste grupo com o estado de conservação do ambiente em que elas vivem, oportunizando reflexões sobre atitudes humanas que impactam diretamente estes seres. Além disso, a metodologia aplicada, proporcionou o desenvolvimento do protagonismo dos estudantes, tornando-os responsáveis pela busca de informações e desenvolvendo neles a capacidade de trabalhar em grupo.

Através da comparação das respostas dadas nos questionários pré-teste e pós-teste, pode-se observar clara mudança de discurso e organização da escrita, tanto semântica quanto sintática, com assimilação e uso de termos próprios da ciência, o que evidencia ocorrência de alfabetização científica. Além disso, este estudo traz dados que demonstram que a observação de aves pode ser facilmente utilizada como uma prática inovadora para o ensino de biologia, abordando diversos temas de maneira contextualizada e interdisciplinar, favorecendo uma aprendizagem não fragmentada.

\section{Agradecimentos}

O presente trabalho foi realizado com apoio da Coordenação de Aperfeiçoamento de Pessoal de Nível Superior (CAPES) - Brasil - Código de Financiamento 001 e, portanto, nossa gratidão a esta renomada instituição.

Nosso reconhecimento e mais sinceros agradecimentos aos estudantes participantes desta pesquisa.

\section{Referências}

Alvares, C. A., Stape, J. L., Sentelhas, P. C., Gonçalves, J. D. M., \& Sparovek, G. (2013). Köppen's climate classification map for Brazil. Meteorologische Zeitschrift, 22(6), 711-728.

Alves, J. F., Silva, L. B. da, \& Reis, D. A. dos. (2020). Reflexões sobre metodologias do ensino de Biologia. Research, Society and Development, 9(8), e850985951. https://doi.org/10.33448/rsd-v9i8.5951

Amabis, J. M.; \& Martho, G. R. (2016). Biologia moderna: Amabis e Martho. Moderna.

Brasil. (2006). Orientações Curriculares para o Ensino Médio: Ciências da natureza, matemática e suas tecnologias. Secretaria de Educação Básica. Brasília: Ministério da Educação, Secretaria de Educação Básica, Brasil.

Brasil. (2018). Base Nacional Comum Curricular: Ensino Médio. Brasília: Ministério da Educação, Secretaria de Educação Básica, Brasil.

Carvalho, A. D., Vannucchi, A. I., Barros, M. A., Gonçalves, M. E. R., \& Rey, R. D. (2005). Ciências no ensino fundamental: o conhecimento físico. Scipione, $7-16$.

Cleophas, M. G. (2016). Ensino por investigação: concepções dos alunos de licenciatura em Ciências da Natureza acerca da importância de atividades investigativas em espaços não formais. Revista Linhas, 17(34), 266-298.

Diesel, A., Baldez, A. L. S., \& Martins, S. N. (2017). Os princípios das metodologias ativas de ensino: uma abordagem teórica. Revista Thema, 14(1), 268288 .

Google. (2020). Google Earth website. https://www.google.com.br/intl/pt-BR/earth/.

Hanzen, S. M., tavares, P. R. D. A., \& Gimenes, M. R. (2015). O acréscimo do conhecimento sobre aves aplicado à educação ambiental na escola Estadual Senador Filinto Müller no município de Ivinhema-MS. Atualidades Ornitológicas, (188), 29.

IBGE. Instituto Brasileiro de Geografia e Estatística. (2010). Cidades. https://cidades.ibge.gov.br/brasil/mt/juina/panorama.

Lei n. 9.394, de 20 de dezembro de 1996. Estabelece as diretrizes e bases da educação nacional. Presidência da República.

Lemke, J. L. (1997). Aprender a hablar ciencia: lenguaje, aprendizaje y valores (No. 04; Q223, L4.). Paidós.

Mato Grosso. (2010) Orientações Curriculares: Área de Ciências da Natureza e Matemática - Educação Básica. SEDUC/MT.

Mette, G., Silva, J. C. D., \& Tomio, D. (2010). Trilhas interpretativas na mata atlântica: uma proposta para educação ambiental na escola. REMEA-Revista Eletrônica do Mestrado em Educação Ambiental, 25.

Mucelin, C. A., \& Bellini, M. (2008). Lixo e impactos ambientais perceptíveis no ecossistema urbano. Sociedade \& natureza, $20,111-124$. 
Research, Society and Development, v. 10, n. 11, e476101119674, 2021

(CC BY 4.0) | ISSN 2525-3409 | DOI: http://dx.doi.org/10.33448/rsd-v10i11.19674

Santos, D., \& Praça, A. (2015). Conhecimento da avifauna pelos alunos do ensino médio do Instituto Marcos Freitas (IMF) Unidade Duque de Caxias (Rio de Janeiro, Brasil). Atualidades Ornitológicas On-line, (187), 55-60.

Santos, C. F. D., Silva, L. G. D. L., \& Lima, R. N. (2012, July). Aves: análise comparativa das informações em livros didáticos de biologia. In VII CONNEPICongresso Norte Nordeste de Pesquisa e Inovação.

Sasseron, L. H. (2015). Alfabetização científica, ensino por investigação e argumentação: relações entre ciências da natureza e escola. Ensaio Pesquisa em Educação em Ciências (Belo Horizonte), 17, 49-67.

Silva, V. A., Souza, C. R., Albuquerque, J. P., Santos, V. F., Nunes, J. R. S., \& Añez, R. B. S. (2017). Levantamento da Avifauna de Um Trecho de Mata Ciliar do Córrego Buriti, Tangará da Serra-MT. (Cap. 3, pp. 27-32). Editora da UNEMAT.

Souza, A. P. A., Silva, J. R., Arruda, R. M., Almeida, L. I. M. V., \& de Carvalho, E. T. (2014). A necessidade da relação entre teoria e prática no ensino de ciências naturais. Revista de Ensino, Educação e Ciências Humanas, 15.

Tabanez, M. F., Pádua, S. M., Souza, M. D. G. D., Cardoso, M. M., \& Garrido, L. M. A. G. (1997). Avaliação de trilhas interpretativas para educação ambiental. Educação ambiental: caminhos trilhados no Brasil, 89-102.

Vieira, V., Bianconi, M. L., \& Dias, M. (2005). Espaços não-formais de ensino e o currículo de ciências. Ciência e Cultura, 57(4), 21-23.

Vieira-da-Rocha, M.C., \& Molin, T. A. (2010). Observação de aves como ferramenta para interdisciplinaridade no ensino de ciência. Atualidades Ornitológicas On-line, 1 (155), 40-48.

Zanin, E. M. (2006). Projeto trilhas interpretativas - a extensão, o ensino e a pesquisa integrados à conservação ambiental e à educação. Vivências, 1(1), 26-35. 